\title{
Spontanoeus lateral abdominal wall hematoma as a complication of coughing: Case report and literature review
}

\author{
$\operatorname{Kasım~Çağlayan~}^{a *}$, Atilla Çelik $b$

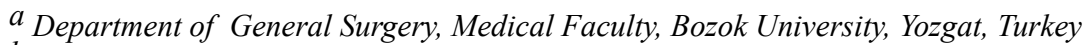 \\ ${ }^{b}$ Department of General Surgery, Haydarpasa Numune, Training and Research Hospital, Istanbul, Turkey
}

\begin{tabular}{|c|c|}
\hline ARTICLE INFO & ABSTRACT \\
\hline $\begin{array}{ll}\text { Article History } & \\
\text { Received } & 01 / 07 / 2010 \\
\text { Accepted } & 13 / 07 / 2010\end{array}$ & $\begin{array}{l}\text { Spontaneous abdominal wall hematoma is a rare condition. In this report, we present a case } \\
\text { of a } 68 \text { Year-old female with right lower abdominal pain. Moderate soft tissue swelling was } \\
\text { palpated in the lateral abdominal wall that was noticed after coughing by the patient. The }\end{array}$ \\
\hline $\begin{array}{l}\text { Correspondence to: } \\
\text { Kasim Caglayan } \\
\text { Bozok Üniversitesi Tıp Fakültesi } \\
\text { Adnan Menderes Bulvarı No:190 } \\
\text { Yozgat. Turkey }\end{array}$ & $\begin{array}{l}\text { patient had no bleeding diathesis and did not use any medication. Abdominal computerized } \\
\text { tomography revealed a } 7 \times 4.5 \mathrm{~cm} \text { hematoma in the right lateral abdominal wall. The patient } \\
\text { has no predisposing factor can be an only reason of lateral abdominal wall hematoma } \\
\text { without coughing. } \\
\text { J. Exp. Clin. Med., 2010; } 27: 35-38\end{array}$ \\
\hline
\end{tabular}

e-mail : kasimcaglayan@hotmail.com

Key Words :

Spontanoeus

Abdominal wall

Hematom

Coughing

Complication

Case report

C 2010 OMU All rights reserved

\section{Introduction}

Abdominal pain is a common problem in the emergency department. Acute abdominal pain and a palpable mass after muscular strain such as coughing, sneezing, and twisting, were features highly suggestive of abdominal wall hematoma. Abdominal wall hematoma is a rare cause of acute abdominal disorders and may be misdiagnosed from other causes of abdominal pain (Chi-Ming et al., 2005).

Abdominal wall hematomas are uncommon. The most common abdominal wall hematoma is spontaneous rectus sheath hematoma caused by the rupture of either the distal branch of the inferior epigastric artery or deep circumflex iliac artery, but a spontaneous hematoma involving the lateral abdominal wall is extremely rare (Nakayama et al., 2008). It may mimic other acute abdominal disorders and is more commonly seen in elderly women, particularly if they are under anticoagulant therapy, or have a chronic cough or cardiovascular disease (Ozaras et al., 2003).

We present a patient who visited in our emergency department with acute right lower abdominal pain and swelling due to spontaneous lateral abdominal wall hematoma that subsequently diagnosed by ours.

\section{Case Report}

A 68 year-old female who admitted to general surgery clinic, was complaining of right lateral abdominal wall swelling and local pain in this region. Patient had no history of trauma, anticoagulant therapy, or coagulation disorder. He explained a history of coughing before abdominal wall swelling, but had no diagnosed pulmonary disease. The patient noticed a swelling in the right lateral abdominal wall one day after coughing.

In systemic examination; patient's blood pressure was $150-90 \mathrm{mmHg}$, heart rate 95 beats/minute and nonarrhythmic and respiratory rate 28/minute. Abdominal examination, hard, smooth, and tender mass, $8 \mathrm{~cm}$ in diameter was palpated in his right lateral abdomen. There was no visible ecchymosis in this area. Laboratory findings were as follows: hematocrit $40 \%$, hemoglobin $13.4 \mathrm{~g} / \mathrm{dl}$; platelets $244.000 / \mathrm{mm}^{3}$, white blood count (WBC) $10.500 /$ $\mathrm{mm}^{3}$, prothrombin time (PT) $28 \mathrm{sec}$, activated partial thromboplastin time (aPTT) $34 \mathrm{sec}$, and international 
normalization ratio (INR) 1.2. Computed tomography (CT) examination performed at admission which showed hyper-dense fusiform mass that situated between oblique abdominal muscles. Average attenuation value of mass was 78 Hounsfield Unite (HU) (Fig. 1A,B). Then, fine needle aspiration of the lesion was performed and revealed hemorrhagic material. The patient was followed two days without any treatment and charged. After 25 days, at control, the diameter of mass was decreased to $4 \mathrm{~cm}$.

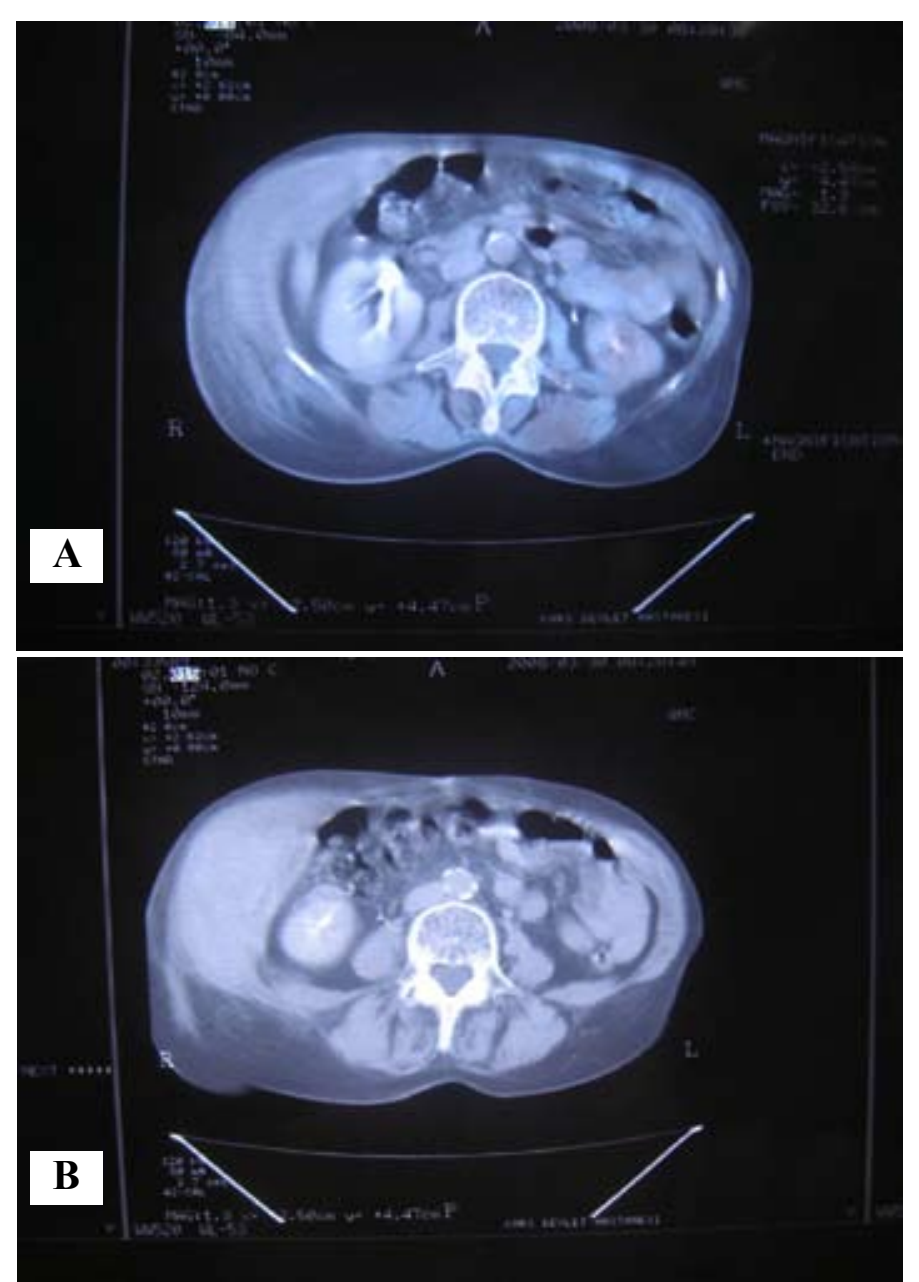

Fig. 1A,B: Show abdominal computed tomography scans of the hematoma in the right oblique muscles of the abdominal wall.

\section{Discusson and literature review}

Hematomas of the abdominal wall or retroperitoneal cavity have been reported as a cause of acute abdomen (Shimizu et al., 2003). An expanding hematoma of the abdominal wall is a rare example of an acute abdominal disease. Spontaneous rectus sheath hematomas caused by the rupture of the inferior epigastric artery is a rare but well-known acute abdominal disease (Zainea and Jordan , 1988). Linhares et al. reviewed 177 cases of spontaneous rectus sheath hematoma in 1999 (Linhares et al.,1999). However, hematomas of the lateral abdominal wall, including both spontaneous and traumatic cases, are very rare (Ikubo et al.,1993; Yamada et al., 1995; Ishihara et al., 2000).

Spontaneous abdominal wall hematoma is considered to occur as a result of non-traumatic injury to vessels or muscles of the abdominal wall, secondary to the following factors: (1) over contraction and overstretching of the muscle, caused by coughing, sneezing, gymnastics, straining, twisting vomiting, etc.; (2) weakness of the vessel's walls or a decrease in muscular resistance, resulting from hypertension, arteriosclerosis, inflammatory disease, pregnancy or delivery, previous surgery, obesity, aging, trauma etc.; or (3) diseases which are characterized by a tendency to bleed or which require the use of anticoagulants (Zainea and Jordan, 1988; Linhares et al., 1999; Casey et al., 2000).

The typical presentation of an abdominal wall hematoma is an acute abdominal pain and a palpable mass after muscular strain in a patient with one or more of the above-mentioned underlying conditions. Very rarely, it may present with urinary retention caused by compression of the bladder (Bene et al., 1998). Physical examination usually reveals a tender abdominal mass of the lower abdomen. The condition may mimic different abdominal pathologies such as appendicitis, sigmoid diverticulitis, perforated ulcer, ovarian cyst torsion, intestinal obstruction, ectopic pregnancy, abruptio placenta, tumor, or hernias (Ramirez et al., 1997; Klingler et al., 2000; Ozaras et al., 2003). Questioning underlying diseases or conditions, any precipitating event, and abdominal examination are vitally important. Thus the diagnosis of abdominal wall hematoma should begin with a careful history and physical examination.

In our case, the spontaneous hemorrhage originated the distal branch of the inferior epigastric artery or deep iliac circumflex artery presumably may result from a probable rupture of the weakness arterial wall resulting from arteriosclerosis and aging. It was probably induced by over contraction and overstretching of the internal oblique muscle at the time of coughing.

Similarly, there have been several case reports of spontaneous rectus sheath hematomas caused by rupture of either the inferior epigastric artery or the deep iliac circumflex artery, and a few reports of internal oblique hematoma as a result of rupture of the deep iliac circumflex artery and subcostal artery (Katsumari and Nakajima, 1998; Tomoharu et al., 2003; Chi-Ming et al., 2005; Nakayama et al., 2008, ).

Anticoagulation and bleeding disorders are well known risk factors for spontaneous hemorrhage and abdominal wall hematomas (Shimizu et al., 2003). They may occur spontaneously or result from trauma, trocar placement or femoral artery catheterization. In our case, the patients were not taking any drugs affecting blood coagulation, and the laboratory data showed that coagulation and bleeding times were within the normal ranges at the time of admission. Furthermore the patient was not traumatized and had no any predisposing factor out of coughing. We thus concluded that, in this patient, distal branch of the deep circumflex iliac artery or inferior epigastric artery was ruptured as a result of muscle over contraction during persistent coughing.

Accurate differential diagnoses for acute 
abdominal diseases are important for prevention of non therapeutic laparotomy. Abdominal wall hematomas have been mistaken for common acute abdominal diseases, such as appendicitis, urinary obstructions, acute cholecystitis, incarcerated inguinal hernias, dissecting aortic aneurysms, mesenteric vascular insults, pregnancy, and torsion of an ovarian cyst (Lohle et al., 1995).

Ultrasonography (US) and CT are useful diagnostic modalities for abdominal wall hematoma (Zainea and Jordan, 1988; Moreno Gallego et al., 1997; Adeonigbagbe et al., 2000). The main advantage of US is its ease of use and widespread availability.

Moreno Gallego et al., (1997) reported that ultrasound and CT examinations are useful imaging methods for the diagnosis of abdominal rectus sheath hematomas, reducing the possibility of unnecessary surgery.

Whereas US findings are not specific and they can be even inconclusive sometimes, CT permits the correct diagnosis (Fukuda et al., 1996). Contrast-enhanced CT can be used not only for differential diagnosis but also for evaluating active bleeding from the rupture site of feeding arteries. The classification (slight, moderate and severe) has been made based on the CT findings (Berná et al.,1996). In our case, a CT was performed for certain diagnosis of the lesion.

The majority of these patients are treated conservatively with ice, bed rest, intravenous hydration, and analgesia if no hemodynamic dysfunction is present. Most hematomas resolve with time (Zainea and Jordan, 1988; Dubinsky, 1997; Adeonigbagbe et al., 2000). Surgery is indicated for those cases with a large hematoma that have undergone bleeding, a rupture into the peritoneal cavity, infection or severe pain resulting in restricted mobility and breathing (Dubinsky, 1997; Klingler et al., 2000). Surgical intervention includes evacuation of the hematoma and ligation of the offending epigastric vessel (Zainea and Jordan, 1988). Recently, several reports have demonstrated that angiography with embolisation can control bleeding and avoid surgical intervention in some cases (Katsumari and Nakajima, 1998; Tomoharu et al., 2003).

But, if the patient had no hemodynamic instability on admission or hematoma is not enlarging in course of time, conservative treatment is acceptable. Not only can the enlargement of the hematoma but also regression evaluate with CT, US or clinical examination. We prefer the clinical follow up because of cost effectiveness and practical.

In our patient, we did not need interventional procedures for treatment and we advised resting and antitussive therapy for preventing possible cough.

Patients presenting with acute abdominal pain and a palpable mass after straining or strenuous activity may have a spontaneous abdominal wall hematoma.

In conclusion, for the emergency physicians and surgeons accurate differential diagnosis for acute abdominal pain is important because it can determine appropriate treatment. Abdominal wall hematoma should be considered in the differential diagnosis of acute abdominal pain. Risk factors such as coagulopathy, cough, or any muscular strain may not precede the development of a palpable, tender mass of lower abdominal pain: it may develop in the absence of underlying diseases or conditions. CT is the diagnostic method of choice. The treatment is usually conservative, as in our case, although surgical treatment or angiography with embolisation may be needed for some patients.

\section{REFERENCES}

Adeonigbagbe, O., Khademi, A., Karowe, M., Gualtieri, N., Robilotti, J., 2000. Spontaneous rectus sheath hematoma and an anterior pelvic hematoma as a complication of anticoagulation. Am. J. Gastroenterol. 95, 314-315.

Bene, J., Lassman, D., Solomon, S.A., 1998. Rectus sheath haematoma in elderly patients: a diagnostic challenge. Age Ageing. 27, 512-514.

Berná, J.D., Garcia-Medina, V., Guirao, J., Garcia-Medina, J., 1996. Rectus sheath hematoma: diagnostic classification by CT. Abdom. Imaging. 21, 62-64.

Casey, R.G., Mahmoud, M., Carroll, K., Hurley, M., 2000. Rectus sheath haematoma: an unusual diagnosis. Ir. Med. J. 93, 90-92.

Chi-Ming, T., Kao-Lang, L., Chieh-Chang, C., 2005. Lateral abdominal wall hematoma due to tear of internal abdominal oblique muscle in a patient under warfarin therapy. Am. J. Emerg. Med. 23,911-912.

Dubinsky IL. 1997. Hematoma of the rectus abdominis muscle: case report and review of the literature. J. Emerge. Med. 15,165-167.

Fukuda, T., Sakamoto, I., Kohzaki, S., Uetani, M., Mori, M., Fujimoto, T., Hayashi, K., Matsuo, S., 1996. Spontaneous rectus sheath hematomas: clinical and radiological features. Abdom. Imaging. 21, 58-61.

Ikubo, A., Komura, M., Matoba, N., Fujii, T., Satoh, K., Masuda, H., 1993. Lumbar artery pseudoaneurysm: an unusual cause of a retroperitoneal hematoma: report of a case. Surg. Today. 23, 635-638.

Ishihara, S., Yasuhara, H., Ogawa, S., Muto, T., 2000. Successful surgical treatment for spontaneous retroperitoneal hematoma in polycythemia vera: report of a case. Surg. Today. 30, 199-201.

Katsumari, T., Nakajima, K., 1998. A case of spontaneous hemorrhage of the abdominal wall caused by the rupture of a deep iliac circumflex artery treated by transcatheter arterial embolization. Eur. Radiol. 8,550-552. 
Klingler, P.J., Oberwalder, M.P., Riedmann, B., Devault, K.R., 2000. Rectus sheath hematoma clinically masquerading as sigmoid diverticulitis. Am. J. Gastroenterol., 95,555-556.

Linhares, M.M., LopesFilho, G.J., Bruna, P.C., Ricca, A.B., Sato, N.Y., Sacalabrini, M., 1999. Spontaneous hematoma of the rectus abdominis sheath: a review of 177 cases with report of 7 personal cases. Int. Surg. 84, 251-257.

Lohle, P.N., Puylaert, J.B., Coerkamp, E.G., 1995. Nonpalpable rectus sheath hematoma clinically masquerading as appendicitis: US and CT diagnosis. Abdom. Imaging. 20,152-154.

Moreno Gallego, A., Aguayo, J.L., Flores, B., 1997. Ultrasonography and computed tomography reduce unnecessary surgery in abdominal rectus sheath haematoma. Br. J. Surg. 84, 1295-1297.

Nakayama, T., Ishibashi, T., Eguchi, D., Yamada, K., Tsurumaru, D., Sakamoto, K., Hidaka, H., Masuda, H., 2008. Spontaneous internal oblique hematoma successfully treated by transcatheter arterial embolization. Radiat. Med. 26, 446-449.

Ozaras, R., Yilmaz, M.H., Tahan, V., Uraz, S., Yigitbasi, R., Senturk, H., 2003. Spontaneous hematoma of the rectus abdominis muscle: a rare cause of acute abdominal pain in the elderly. Acta. Chir. Belg. 103, 332-333.

Ramirez, M.M., Burkhead, J.M., Turrentine, M.A., 1997. Spontaneous rectus sheath hematoma during pregnancy mimicking abruptio placenta. Am. J. Perinatol. 14, 321-323.

Shimizu, T., Hanasawa, K., Yoshioka, T., 2003. Spontaneous hematoma of the lateral abdominal wall caused by a rupture of a deep circumflex iliac artery: report of two cases. Surg. Today. 33, 475-478.

Tomoharu, S., Kazuyoshi, H., Toyokazu, Y., 2003. Spontaneous hematoma of the lateral abdominal wall caused by a rupture of a deep circumflex iliac artery: report of two cases. Surg. Today. 33, 475-478.

Yamada, M., Nonaka, M., Murai, N., Hanada, H., Aiba, M., Funami, M., 1995. Spontaneous rupture of the iliac vein: report of a case. Surg. Today. 25, 465-467.

Zainea, G.G., Jordan, F., 1988. Rectus sheath haematoma: their pathogenesis, diagnosis, and management. Am. Surg. $54,630-633$. 